\title{
AN OGIVE SHAPED CARBON-CARBON COMPOSITE BEAM STOP*
}

\author{
R. T. Acharya, D. W. Doll, K. Redler, T. Van Hagan, General Atomics, San Diego, CA
}

\begin{abstract}
An ogive shaped carbon-carbon composite (CCC) beamstop has been designed to replace the original nickel ogive beam stop for the Low Energy Development Accelerator (LEDA) of the APT (Accelerator Production of Tritium) project. The nickel beamstop has been used for initial testing of the $6.7 \mathrm{MeV}, 100 \mathrm{~mA} \mathrm{cw}$ proton beam from the APT RFQ (Radio Frequency Quadrupole). Because of activation concerns, another beam stop is needed for future tests on the first module of the Coupled-Cavity Drift-Tube Linac (CCDTL), which will increase proton beam energy to $10.4 \mathrm{MeV}$. The CCC ogive has been integrated into the nickel structure as a direct replacement. The design and fabrication of the CCC ogive beamstop is presented with a review of the original nickel ogive design.
\end{abstract}

\section{BACKGROUND}

Beamstops have been designed to accommodate each level of LEDA [1] testing as part of the APT program [2] The injector was tested $\mathrm{cw}$ through a low energy RFQ to $1.2 \mathrm{MeV}$ into an ogive shaped copper target [3]. A second beamstop was designed and built for testing the RFQ to $6.7 \mathrm{MeV}$ and $100 \mathrm{~mA}$ [3]. Unlike the first ogive, which operated below the threshold of neutron production, this target was made from nickel in order to minimize the neutrons per proton $(\mathrm{n} / \mathrm{p})$ ratio while being structurally compatible with the vacuum and cooling water requirements. As successive segments of the CCDTL are added to the RFQ raising the proton energy, the $\mathrm{n} / \mathrm{p}$ and activation products become too high to permit the required access flexibility during commissioning. A low $\mathrm{n} / \mathrm{p}$ ratio is necessary in the target and the surrounding structural materials need to have short half-life activation products.

A carbon target satisfies the low $\mathrm{n} / \mathrm{p}$ ratio and low activation criteria best [4]. However, it is unsuitable as a primary vacuum barrier and is not compatible with traditional metal seals and flanges. Nickel activates from neutrons but these activation products have a short halflife. An optimum solution to the problem is a carbon lining bonded directly to the inside of an ogive shaped nickel backing that replaces the existing beamstop. This provides a carbon target for the protons and a nickel vacuum barrier to seal the vacuum from the water coolant. This paper addresses the design of such a beamstop configured to upgrade the LEDA installation to $10 \mathrm{MeV}$ operation.

\footnotetext{
* Work supported by the Department of Energy contract No. DEAC04-96AL89607
}

\section{DESCRIPTION}

The cartridge containing the CCC target replaces the one originally installed for $6.7 \mathrm{MeV}$ operation. In all external features, including hydrophones for boiling detection, it is the same as its predecessor. The cartridge housing made from nickel, is $3.2 \mathrm{~m}$ long by $0.23 \mathrm{~m}$ in diameter; the target contained in it is ogive shaped with a close fitting shroud that directs cooling water from the aft end over the outer surface through a $4 \mathrm{~mm}$ gap (Figure 1 ). The water exits the gap at the forward end where the beam enters, turns 180 degrees, then returns to the aft end where it exits to the cooling-cart. This cooling-cart was designed initially to be upgraded to $10.4 \mathrm{MeV}$ operation (1 MW) and will remain unchanged.

The ogive is made from a special CCC, $2.5 \mathrm{~mm}$ thick, on which a $2.5 \mathrm{~mm}$ thick layer of nickel is electrodeposited. The CCC thickness is set by the $0.76 \mathrm{~mm}$ range of a $10 \mathrm{MeV}$ proton in $1.65 \mathrm{~g} / \mathrm{cm}^{3}$ carbon and stress considerations. The nickel layer is subsequently (electroform) joined to a nickel flange at the beam opening and to a wheel-and-spokes shaped support at the pointed end. The CCC utilizes polyacrylonitrile (PAN) fibers in mat form with the fibers running axially and circumferentially. The multiple layers (approximately 11) have their joints overlapping out of phase and are bound together through their thickness with cross stitches (tufting) comprising about 3\% of the fiber volume. This provides the required strength in the transverse direction.

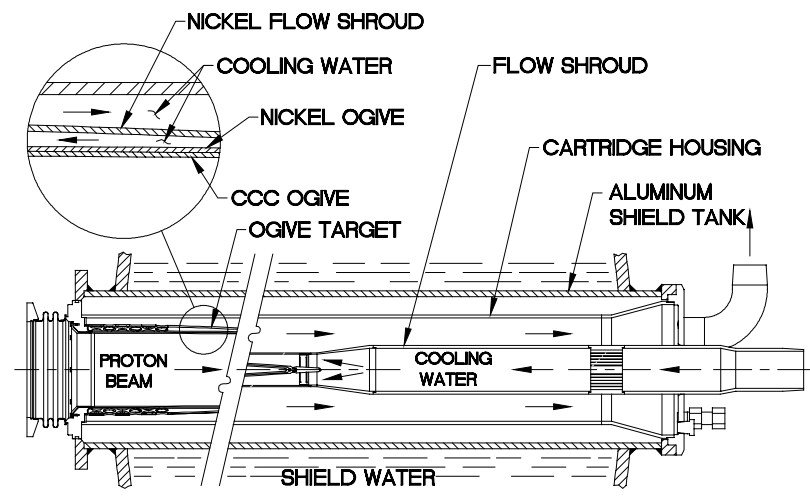

Figure 1: Cross section of beamstop cartridge showing CCC ogive target

\section{MATERIALS SELECTION}

Materials of construction were selected on the basis of nuclear, thermal, and mechanical properties. A tensile test was run to confirm the CCC-to-nickel bond strength. 


\subsection{Nuclear Considerations}

One of the key considerations in the choice of materials is radiation exposure to linac operating personnel. This radiation exposure has two components. The first component is from the prompt neutrons and gammas produced in the stopping material. Prompt radiation is of little importance since the area is clear of personnel during accelerator operation. The second component of the radiation exposure is from gammas emitted by the activated materials. This includes the concentric layers that make up the cartridge and inner liner of the shield tank. The radiation dose from these components affects personnel access to areas near the beamstop immediately after the beam shut-down. Minimizing neutron production minimizes both components of radiation exposure (Fig. 1).

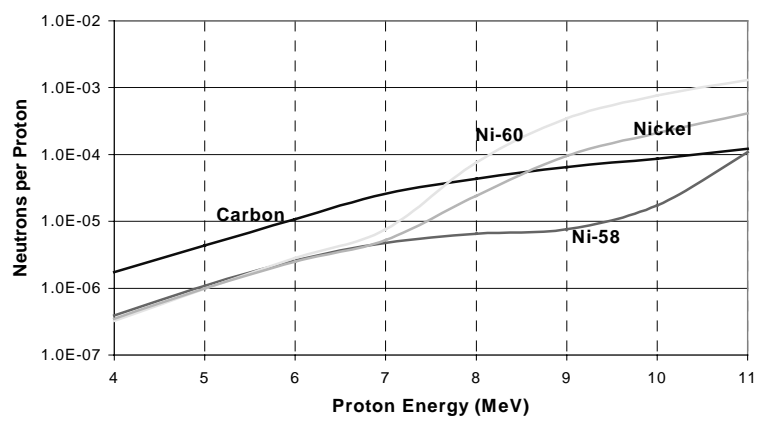

Figure 1: n/p ratio as function of proton energy

A carbon target [5] with nickel structures satisfies both the need to minimize neutron production and inventory of long half-life activation products. Stainless steel (SS), used for the original cartridge housing, was rejected for the replacement because the $\mathrm{Fe}-59$ and $\mathrm{Cr}$ 51 produced by neutrons (Table 1) have relatively long half-lives and emit high energy gammas when they decay.

Table 1: Neutron Activation Products from Beamstop Materials

\begin{tabular}{|l|l|l|}
\hline Isotope & Half-life & $\gamma$ Energy $(\mathrm{MeV})$ \\
\hline $\mathrm{C}-12$ & ----- & ----- \\
\hline $\mathrm{Ni}-65$ & $2.52 \mathrm{~h}$ & 1.46 \\
\hline $\mathrm{Cu}-64$ & $12.8 \mathrm{~h}$ & 1.34 \\
\hline $\mathrm{Cr}-51$ & $27.7 \mathrm{~d}$ & 0.321 \\
\hline $\mathrm{Fe}-59$ & $44.51 \mathrm{~d}$ & $1.099,1.291$ \\
\hline $\mathrm{Na}-24$ & $14.96 \mathrm{~h}$ & $1.37,2.75$ \\
\hline
\end{tabular}

$\mathrm{C}-12$ (99\%) produces no neutons at proton energies below $19.6 \mathrm{MeV}$; below this threshold, C-13 (1\%) produces neutrons in a ${ }^{13} \mathrm{C}+\mathrm{p}==>{ }^{13} \mathrm{~N}+\mathrm{n}$ reaction. Nickel becomes Ni-65 with a 2.52-h half-life. Although the gamma energy associated with this decay is high, its half-life is short. The dose rate near the beamstop will be low after a one to two day cool-down period. The aluminum shield tank inner liner activates to produce $\mathrm{Na}-24$, which decays with the emission of very highenergy gammas. It will reach equilibrium levels within 2 to 3 days of continuous beamstop operation. Supplemental shielding will be needed if unlimited access to the areas near the beamstop is necessary soon after the beam is turned off.

\subsection{Bond Strength Test}

Six $25 \mathrm{~mm}$ diameter by $3 \mathrm{~mm}$ thick CCC disks with 0.5 $\mathrm{mm}$ of electroformed nickel on one side were tensile tested to determine the adhesion strength of the coatingto-substrate bond. Testing was based upon ASTM Specification No.C633-79. While the tests demonstrated that the electroformed nickel coating is well adhered to the CCC substrate, the actual strengths of the bonds for the test specimens could not be determined directly. This was because the CCC was not tufted, which resulted in low transverse tensile strength. With tufting, a transverse tensile strength of $20 \mathrm{~Pa}(3000$ psi) could be expected. Consequently, five of the six test specimens failed in the CCC near the uncoated face at 3.5 to $5 \mathrm{MPa}$ (510 to $730 \mathrm{psi}$ ). The sixth specimen failed at $6.2 \mathrm{MPa}(895 \mathrm{psi})$ in the adhesive under at the interface between the nickel coating and the steel test fixture. From these data, it was shown that the bond strength withstood the highest applied stress, 6.2 MPa.

Remnant pieces of the coated CCC panel were also examined by scanning electron microscopy (SEM) to characterize the coated CCC material. SEM and energy dispersive X-ray (EDX) examinations showed that the coating was essentially pure nickel with slight traces of carbon and oxygen. An EDX examination of the CCC near the nickel coating showed traces of oxygen, silicon, sulfur and nickel. SEM photographs (Fig. 2) show a pore-free coating that is well attached or bonded to the CCC substrate. A few traces of the nickel coating material and impurities from the electroforming process can be observed to a depth of approximately $1.2 \mathrm{~mm}$ into the CCC. This is still beyond the range of the $10 \mathrm{MeV}$ protons.

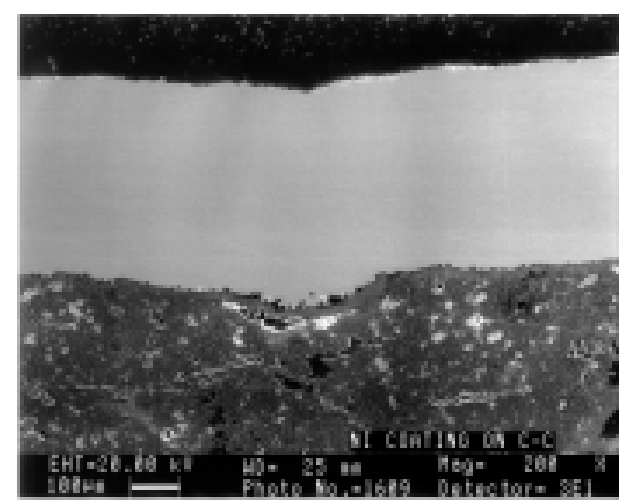

Figure 2: SEM image of the nickel/CCC interface

\section{THERMAL AND STRESS ANALYSES}

The principal concern with a CCC/nickel lamination is the large difference in thermal expansion of the two materials. The nickel is electroformed at room 
temperature, leaving no residual stress. However, the thermal and mechanical properties in the CCC vary depending on the choice of carbon fibers and curing temperature. Curing at a high temperature $\left(2500^{\circ} \mathrm{C}\right)$ results in an increase in the transverse thermal conductivity and in-plane tensile modulus. This correspondingly causes a reduction in the in-plane (fiber) CCC strength; curing at a lower temperature $\left(1200^{\circ} \mathrm{C}\right)$ maintains the in-plane tensile strength but results in a lower in-plane tensile modulus and transverse thermal conductivity.

Two cases were analyzed. The first case used the properties of T-300, a PAN-based carbon fiber CCC cured at $1200^{\circ} \mathrm{C}$. The second case used the properties of $\mathrm{K} 321$, a pitch-based carbon fiber CCC cured at $2500^{\circ} \mathrm{C}$. The thermal and mechanical properties of both materials show that graphitization of the composite increases the thermal conductivity by a factor of 14 in the in-plane direction and by a factor of 2 in the transverse direction. However, the in-plane strength decreases by a factor of 1.8 , and the tensile modulus increases by a factor of 1.5. This made it necessary to determine whether the benefits of increased thermal conductivity (i.e., decrease in temperature gradient through the thickness and a lower surface temperature) were enough to offset the increase in modulus (i.e., higher stress caused by the deformation due to the expanding nickel) and the decrease in transverse tensile strength.

An axisymmetric ANSYS model was created as a thin slice through the thickness of the ogive at the location of the peak heat flux, $68.6 \mathrm{~cm}$ from the entrance of the beamstop. The peak heat flux is $264 \mathrm{~W} / \mathrm{cm}^{2}$ applied to the inner surface of the model. The cooled outer surface has a heat transfer coefficient of $2.97 \mathrm{~W} / \mathrm{cm}^{2}-\mathrm{K}$ and a fluid bulk temperature of $26.6^{\circ} \mathrm{C}$. The slice is free to expand radially. In the axial direction, the rear surface is constrained not to move, and all the nodes on the opposing surface are constrained to move equally.

The results for both types of CCC are shown in Table 2. The stress in the T-300 CCC is lower than in $\mathrm{K} 321$ due to the lower modulus of elasticity of T-300 indicating that it is more compliant to the expanding nickel. Similarly, the Von Mises stress in the nickel is lower with the T-300.

With the T-300 PAN CCC selected, it was necessary to optimize its thickness as well as that of the nickel. By limiting the overall ogive thickness to $5.08 \mathrm{~mm}$, varying the interface and analyzing the resulting stress, an optimum was derived. The results show that as the thickness of the nickel increases, the stresses in both the nickel and the CCC increase indicating that the nickel should be as thin as possible. However, in order to prevent the ogive from buckling due to the external hydraulic pressure from the coolant $0.55 \mathrm{MPa}$ (80 psi), the nickel thickness was set at $2.5 \mathrm{~mm}$ to assure that it acts alone in withstanding the pressure. The minimum thickness of the nickel ogive to withstand 3 times the external pressure is $2.41 \mathrm{~mm}$, a reasonable margin of safety. The transverse tensile stress in the CCC is at a maximum in this allowed region for the nickel. However, it is still well below the minimum ultimate for the CCC or the interface bond strength.

Table 2: Calculated stress for T-300 CCC and K321 CCC Ogives bonded to nickel outer surface.

\begin{tabular}{|r|c|c|}
\hline & T-300, PAN & K321, Pitch \\
\hline T beam wall $\left({ }^{\circ} \mathrm{C}\right)$ & 544 & 411 \\
\hline T interface $\left({ }^{\circ} \mathrm{C}\right)$ & 214 & 214 \\
\hline T water wall $\left({ }^{\circ} \mathrm{C}\right)$ & 109 & 109 \\
\hline S radial $(\mathrm{psi})$ & 645 & 898 \\
\hline S axial $(\mathrm{psi})$ & 21500 & 29000 \\
\hline S hoop $(\mathrm{psi})$ & 20800 & 28000 \\
\hline Transverse $\mathrm{S}_{\mathrm{ult}}(\mathrm{psi})$ & 3000 & 3000 \\
\hline In-Plane $\mathrm{S}_{\mathrm{ult}}(\mathrm{psi})$ & 54200 & 30200 \\
\hline
\end{tabular}

\section{CONCLUSIONS}

A beamstop has been designed to accommodate the upgrade of the LEDA from RFQ operation at $6.7 \mathrm{MeV}$ to $10 \mathrm{MeV}$ CCDTL operation. It utilizes an ogive shaped carbon-carbon composite liner intimately bonded to a nickel backing to satisfy the thermal and mechanical requirements while minimizing the inventory of activated materials. The uncertainty in the transverse tensile strength remains a concern. The margin of safety is small, and the properties are tied to the densification and curing, a somewhat art-driven proprietary process. This too can be said of the electroforming process that forms the nickel over the carbon. Demonstration of this technology will enable similar beamstop designs to be developed.

\section{ACKNOWLEDGEMENTS}

The authors wish to thank Dr. J. D. Schneider and his associates at LANL for their encouragement in pursuing this technology. We thank Albany Technoweave, Inc., Refractory Composites, Inc., and American Galvano, Inc. for their CCC and electroforming expertise.

\section{REFERENCES}

[1] H. V. Smith, Jr., J. D. Schneider, "Status Update on the Low Energy Demonstration Accelerator (LEDA)", XIX International Linac Conference, August 23-28, 1998, Chicago, Illinois

[2] G. Lawrence, "High-Power Proton Linac for APT; Status of Design and Development", (LEDA), XIX International Linac Conference, August 23-28, 1998, Chicago, Illinois

[3] T. Van Hagan, et al., "Design of an Ogive-Shaped Beamstop", proceedings, XIX International Linac Conference, August 23-28, 1998, Chicago, Illinois

[4] D. Doll, et al., "Low to high Energy Beamstops for APT", XIX International Linac Conference, August 23-28, 1998, Chicago, Illinois

[5] E. A. Burrill, "Direct Nucleon Accelerators," Engineering Compendium on Radiation Shielding, Vol. III, Shield Design and Engineering, 1970 